\title{
A Nobel Prize for Poincaré?
}

\author{
Pietro Nastasi
}

Published online: 16 May 2013

(C) Centro P.RI.ST.EM, Università Commerciale Luigi Bocconi 2013

\begin{abstract}
Gösta Mittag-Leffler campaigned hard to obtain Henri Poincaré's nomination for a Nobel Prize in physics, but unfortunately never succeeded. Other mathematicians and physicists agreed that Poincaré's work deserved recognitions, but physicists on the prize committe had more regard for experimentation than theory. Vito Volterra was among those who supported Poincaré's nomination, pointing out that theoretical research often made experimentation possible
\end{abstract}

Keywords Henri Poincaré · Alfred Nobel · Nobel Prize · Gösta Mittag-Leffler

\section{Mathematics Subject Classification $\quad 01 \mathrm{~A} 74$}

'The interest on [my capital] shall be annually distributed in the form of prizes to those who, during the preceding year, shall have conferred the greatest benefit to mankind.' With these words the industrialist Alfred Nobel (1833-1896) established in his will the difficult task of conferring the prizes that now bear his name. The will specified that the people who had made the most important discoveries in the fields of physics, chemistry, medicine (or physiology), literature and peace were to be honoured, with the stipulation that the candidates' nationality was not to be taken into account. The prizes would be distributed by the Nobel Foundation in the following way: those for chemistry, physics and literature would be awarded by the Swedish Academy of Sciences, with the literary award assigned directly during a plenary session, while those for chemistry and physics were to be assigned on

P. Nastasi ( $\square)$

Via Franco Sacchetti, 7, 00137 Rome, Italy

e-mail: pgnastasi@libero.it the basis of a preliminary selection by two committees consisting of five members each, appointed by the Academy itself. The prize for medicine would be awarded by the Karolinska Institutet of Stockholm (the equivalent of the Academy in the medical field) and that for peace by a committee of five chosen by the Norwegian parliament. ${ }^{1}$ The award ceremonies would always be held on 10 December, the anniversary of Nobel's death.

Henri Poincaré and Gösta Mittag-Leffler had been acquainted since 1881, after Hermite had recommended Poincaré's doctoral thesis to Mittag-Leffler, so it is no wonder that when the Swedish mathematician founded Acta Mathematica, the first ever international mathematical journal, Poincaré contributed not one but two articles, on Fuchsian groups [4] and Fuchsian functions [5]. The two worked together and were good friends for more than 30 years.

When, near the end of the century, Nobel decided how to assign the prizes but neglected mathematics (perhaps because it was a science far from his interests), Mittag-Leffler decided with a clear mind to play the role of advocate for theoretical physics within the Academy of Sciences, of which he had been a member since 1883 [6], p. 677]. Basically, he intended to persuade most academicians that there was more to physics than just its experimental side. If this plan were to succeed, it would be easier, later on, with a well-thought-out report, to obtain a Nobel Prize for Poincaré, focussing on his papers in mathematical physics.

Thus, the strategy chosen by Mittag-Leffler consisted in nominating a theoretical physicist for the second year's prize $^{2}$ in 1902, Dutch physicist Hendrick Lorentz

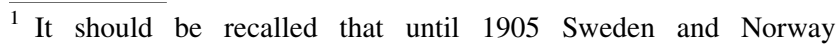
constituted a single kingdom.

2 In 1901, the first Nobel prize for Physics was awarded to Wilhelm C. Röntgen (1845-1923) for his discovery of X-rays.
} 
(1853-1928), as Mittag-Leffler himself wrote to Painlevé on 18 July 1902 [3, p. 306]. It is apparent from this letter that the strategy had been discussed with Poincaré, who wrote the nomination report, later supported by all French physicists and by Röntgen and Planck from Germany. 'If I am successful', Mittag-Leffler wrote, 'I will open the way to theoretical physics, and hence to a Nobel Prize for Poincaré'. Poincaré's indirect answer is in his report supporting the nomination of Lorentz, which he concluded with an interesting defence of the role of theories in physics:

Theories are charged with being fragile and, sure enough, if they claimed to unveil things thoroughly, the very spectacle of so many wrecks would be enough to make us sceptical. But, when Lorentz's theory has reached its forerunners in this vast graveyard, will not the facts it predicted and helped to discover still persist? And if one day this theory were to be abandoned, how wrong would be whoever said that it was by chance that it made us discover true facts since it was later revealed as false? No, it is not by chance, it is because that theory unveiled formerly unknown relationships between seemingly unrelated facts, and these relationships are real; and they would be even if electrons did not exist. This is the kind of truth we can hope to get from a theory, the truth that will survive it [3, p. 313].

Unfortunately, Mittag-Leffler and Poincaré were wrong: they won a battle in 1902, when the Nobel Prize was awarded to Lorentz (and to Zeeman), but they lost the war against most of the committee for physics, who were more interested in experimental physics, which at the end of the nineteenth century had indeed made some remarkable achievements, which were rewarded. ${ }^{3}$

In the years that followed the proposals in favour of Poincaré were repeated, alone or together with Gabriel Lippmann, ${ }^{4}$ who received the prize in 1908 'for his method, based on the phenomenon of interference, which permits the reproduction of colours by photography'. For 1909, Mittag-Leffler deemed it useless to try again and in a letter dated 22 December 1908 [3, pp. 349-350] asked Poincaré for his opinion about a 1909 Nobel Prize for the invention of aeroplane. When Darboux sent him his report

\footnotetext{
3 The components of the first Nobel committee for Physics were: Arrhenius, Hildebrandsson (a meteorologist), Ångström (a young experimentalist), Hasselberg (a spectroscopist), and Thalén (a 75-year old physicist). Of the five, the only one with actual scientific merits was Arrhenius, but he was a chemist. For more details, see [2].

4 To be precise, Poincaré was endorsed for 1904 (report by Becquerel and Darboux), for 1906 (report by Becquerel, Darboux, and Guye), for 1907 (again, a report by Becquerel e Darboux), and for 1909 (report by Darboux, Le Châtelier, and Lippmann).
}

to again nominate Poincaré, ${ }^{5}$ Mittag-Leffler, though embarrassed, confirmed his choice but did not deem the two proposals incompatible. Indeed, in a letter to Painlevé dated 3 February 1909 [3, pp. 351-352], he wrote:

Thanks for your letter and for the very interesting and detailed report. ${ }^{6}$ Together with Poincaré and you, it was endorsed by me, Phragmén, Backlund (Pulkowa), Carlheim-Gyllensköld, and Bendixon. ... If there is the slightest chance that this time Poincaré could get the prize, we would drop our 'heavierthan-air' proposal and would do all possible for Poincaré. But I do not believe that this time Poincaré's nomination will be accepted. The Nobel committee for physics consists of Ångström (president), Granqvist, Hildebrandson, Hasselberg, Arrhenius, a set of people who do not grasp theory at all and are unable to understand one sentence even from Poincaré's popular writings. I gather that Arrhenius had to promise Lippmann to back Poincaré, but as you know he is a duplicitous man, and will not keep his promise.... In spite of everything, I am very happy about the decision of the French to support Poincaré seriously. It will pave the way for next year, when we shall try to gather all the Nobel Prize winners for physics to back a proposal for Poincaré, and it will be successful. I have been preparing this for a long time. It will be crucial to have a good report, in which the prize is to be proposed for a special discovery. As you know, the prize is given to a discovery, not to a man. I will tell you my opinion after reading the report by Darboux, Lippmann, etc. for this year's proposal for Poincaré.

The proposal for 1910 was the high point in MittagLeffler's 'assault' for a Nobel Prize for Poincaré. The main letter was signed by Fredholm and Appell, both professors of mathematical physics, and by Darboux (at the time, secretary of the Académie des Sciences). To be on the safe side, the proposal only mentioned the discoveries in mathematical physics. Several precautions were taken in order not to antagonize or scare the experimental majority of the Nobel committee. Then Mittag-Leffler launched an international campaign in which 34 signatures were gathered around the 'Poincaré proposal', the highest number of

\footnotetext{
5 The proposal had been endorsed by almost all the French physicists.

${ }^{6}$ Painlevé's report suggested sharing the prize between the Wright brothers and the Voisin brothers (builders of a new aircraft) and their pilot Farman. The proposal was not accepted and the 1909 Nobel prize for Physics was awarded to Guglielmo Marconi together with Karl F. Braun.
} 
signatures collected between 1901 and 1930 to back a nomination. $^{7}$

While investigating the reasons that might somehow justify the reluctance to number Poincaré among physicists, Scott Walter, Etienne Bolmont and André Coret, the editors of Poincaré's correspondence with physicists, quote [7, p. xii] the opinion of Poincaré as a physicien géomètre given by Marcel Brillouin while reviewing the second edition (1901) of Poincaré's book Électricité et optique. They add that Poincaré never shed this label, since in the centenary of his birth, in 1954, Louis de Broglie still described him as plus analyste que physicien.

We also have to remark that Poincaré's nomination was seriously compromised by Röntgen, who, on learning that Ångström was very ill, nominated the Swedish physicist for his work on solar radiation. Arrhenius and his entourage hurried to support the nomination but, as a precaution, since Nobel Prizes could not be awarded posthumously, added a nomination for Van der Waals. The committee and the Academy opted for Van der Waals. Thus the 1910 prize went to the Dutch scientist for his work on the equations for gases and liquids.

Vito Volterra had guaranteed the success of the nomination in Italy, using his influence to sway mathematician and physicist Pietro Blaserna (1836-1918), who persisted in putting forward the components of the Comite des Poids et Mesures, as well as the Italian physicists, who had committed themselves to nominating Augusto Righi. ${ }^{8}$ In a letter to Mittag-Leffler, Volterra announced that he had sent his individual nomination for Poincaré 'for his discoveries about the differential equations of mathematical physics'. Volterra then detailed the general significance of these discoveries in the report he sent to the committee for physics (the draft is conserved at the Accademia dei Lincei):

It is not necessary to give many examples in order to show the role and the importance of the differential equations and, in general, the analytic methods for the development of physics. It will suffice to recall that it is through the theoretical study of the general equations of elasticity, and through the comparison of these equations with those of the electromagnetic

\footnotetext{
7 The strong support notwithstanding, the absence of some wellknown British and German physicists stands out. For instance, Rutherford and Thomson refused their endorsement for reasons due basically to defending the interests of the 'true physicists', that is, experimentalists. The weak support by Lorentz and Zeeman is also surprising, since Poincaré had vigorously backed them in 1902.

${ }^{8}$ See the confidentielle letter by Volterra to Mittag-Leffler dated 10 January 1910, conserved at the Institut Mittag-Leffler in Djursholm (Stockholm). See also [1, pp. 85-101], about the report by Padua physicists endorsing Righi for 1910 Nobel prize; this actually weakened Volterra's proposal.
}

field, that Maxwell was led to the creation of the electromagnetic theory of light, and that this theory has been the starting point and the guide for Hertz's research on electromagnetic waves, which in turn gradually led to the discovery of wireless telegraphy. ${ }^{9}$ If Maxwell's theoretical work on differential equations had not been carried out, the most brilliant area of modern physics would not have developed.

The history of physics, and especially it most modern part, shows us that every achievement of physics is increasingly connected to those of analysis, and that this instrument of human thought is the most suitable to rigorously classifying, proving and comparing the phenomena of the physical world, and so to have mastery over them.

Poincaré's papers about the equations of mathematical physics form a body of work of the utmost importance for physics, due to the depth of the ideas they include and to the interest of their applications. They provided for the first time a rigorous and complete solution to a great number of fundamental, long-studied questions in physics.

Volterra was one of the few to continue nominating Poincaré, even in later years, in 1911 and again in 1912, when he supported, as an alternative, the nomination of Righi. Both attempts failed.

Translated from the Italian by Daniele A. Gewurz

\section{References}

1. Caparrini, S., Tazzioli R. (eds.): Alle origini della Fisica teorica. La corrispondenza tra Augusto Righi e Tullio Levi-Civita (1901-1920). PRISTEM Storia: Note di Matematica, Storia e Cultura, 29-30 (2011)

2. Crawford, E.:The Beginnings of the Nobel Institution. The Science Prizes, 1901-1915. Cambridge University Press/Editions de la Maison des Sciences de l'Homme, Cambridge/Paris (1984)

3. Nabonnand, P. (ed.): La Correspondance entre Henri Poincaré et Gösta Mittag-Leffler. Birkhäuser, Basel (1999)

4. Poincaré, H.:Théorie des groupes fuchsiens. Acta Mathematica 1, 1-62 (1882a)

5. Poincare, H.:Mémoire sur les fonctions fuchsiennes. Acta Mathematica 1, 193-294 (1882b)

6. Stubhaug, A.: Gösta Mittag-Leffler. A Man of Conviction. Springer-Verlag, Berlin-Heidelberg (2010)

7. Walter, S., Bolmont, E., A. Coret (eds.): La Correspondance entre Henri Poincaré et les physiciens, chimistes et ingenieurs. Birkhäuser, Basel (2007)

\footnotetext{
9 There is a patent reference to 1909 Nobel presented to Marconi and Braun 'who have contributed most to the development of wireless telegraphy'.
} 


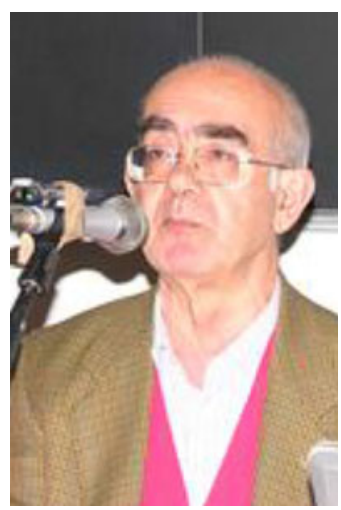

\section{Author Biography}

Pietro Nastasi Formerly a Professor of History of Mathematics at the University of Palermo, works on the modern and contemporary history of mathematics, with a particular focus on institutional aspects. 